\title{
La constitución de la propiedad indígena como fin de la expropiación por interés nacional
}

\author{
Manuel A. Núñez Poblete*
}

\section{RESUMEN}

El presente estudio pretende identificar y explicar la justificación del recurso a la expropiación como instrumento que permite a los Estados cumplir con sus deberes de reparación frente a la desposesión de la propiedad indígena. Para ello el texto identifica la doctrina de los órganos jurisdiccionales y no jurisdiccionales de supervisión de tratados de derechos humanos, la práctica comparada en la región y la viabilidad en el texto vigente de la Constitución de 1980.

Propiedad indígena - expropiación - derecho de restitución y de reparación

\section{The constitution of indigenous property as a goal of expropriation by national interest}

\begin{abstract}
The paper analyses the rationale of expropriation as a State mechanism for restitution before indigenous land claims. The grounds of this institution are identified in the doctrine of international human rights institutions and comparative law in the Americas. Finally, the paper discusses about the constitutionality of expropriation under current Chilean Constitution.
\end{abstract}

Indigenous Property - expropriation - right to restitution and reparation

* Doctor en Derecho, Universidad de Santiago de Compostela. Profesor de Derecho, Facultad de Derecho de la Pontificia Universidad Católica de Valparaíso. Correo electrónico: manuel.nunez@ucv.cl.

El presente trabajo forma parte del Proyecto de investigación núm. 1130665, patrocinado por el Fondo Nacional de Desarrollo Científico y Tecnológico (Fondecyt) y del que el autor es investigador principal. El autor agradece la asistencia de investigación de la Lic. (PUCV) María Gabriela Barros Fuenzalida.

Artículo recibido el 1 de marzo de 2016 y aceptado para su publicación el 1 de marzo de 2017. 


\section{INTRODUCCIÓN}

$\mathrm{L}$ a respuesta a las reivindicaciones territoriales es uno de los problemas acuciantes que enfrentan los Estados con población indígena en la región. Estas demandas indígenas territoriales tienen dos dimensiones: de una parte, pretenden la recuperación de la propiedad sobre las tierras que fueron desposeídas y, de otra, aspiran al diseño de políticas y a la generación de normas que les permitan el control respecto de los territorios que alguna vez les fueron de dominio político. Dentro de la primera de estas dimensiones, se presenta el problema de determinar el procedimiento a seguir cuando los inmuebles se encuentran radicados en un patrimonio diverso al fiscal, situándose la expropiación como una de las herramientas que posibilitan la transferencia de la propiedad de la tierra y, con ello, la satisfacción de la demanda territorial.

El objetivo del presente estudio es examinar el contexto normativo justificativo y, por tanto, la viabilidad jurídica del expediente expropiatorio como instrumento de los gobiernos para cumplir con parte de las obligaciones que el Derecho nacional e internacional les imponen respecto de la tierra indígena. Para estos efectos, la investigación tomará como su eje el objeto reclamado, esto es, la restitución de tierras que fueron previamente ocupadas por miembros de comunidades indígenas y que actualmente se encuentran radicadas en el patrimonio de terceros. A causa de esta última condición, el estudio se aboca a aquellos casos en que no son suficientes las herramientas del derecho privado ordinario (como pueden ser las acciones posesorias, reinvindicatorias, anulatorias de inscripciones conservatorias, etc.) y es preciso, por el contrario, el recurso a las herramientas que por excelencia pertenecen al campo del derecho público. Quiere por tanto el presente estudio aportar a la reflexión acerca de una de las varias dimensiones que tiene la propiedad indígena frente al estatuto jurídico de la expropiación.

Las características de los reclamantes (esto es, si se trata de indígenas individuales, familias, tribus, comunidades legales, etc.), la situación particular de la tierra reclamada (si está o no en posesión material de quienes reclaman, si hay o no demandas de otras comunidades, etc.) o la condición jurídica de sus actuales tenedores, no será aquí analizada, porque el texto solo pretende fijar las coordenadas generales de análisis respecto del instituto expropiatorio. Debido a que el enfoque será eminentemente jurídico, tampoco será objeto de pronunciamiento específico el análisis respecto de la conveniencia política de la expropiación, aunque ciertamente algo se dirá relativa a la reflexión que la teoría política ha dedicado a las demandas territoriales cuando obedecen a aquello que la literatura califica como "injusticias históricas".

Para acometer su objetivo el texto se ha dividido en cuatro partes. La primera parte (II) está dedicada a contextualizar el derecho a la restitución dentro del haz de herramientas que el Derecho internacional reconoce al Estado para reparar el perjuicio generado por la desposesión de tierras. La segunda parte (III) explica las condiciones que explican la eventual conversión de la restitución en formas alternativas de reparación y se identifican someramente las dificultades prácticas y teórico-políticas que obstaculizan la restitución, particularmente cuando se trata de demandas pluriseculares. La tercera y cuarta parte desarrollan la figura de las expropiaciones restitutorias en la doctrina y 
jurisprudencia de los órganos de supervisión y cumplimiento (IV), como asimismo en la legislación de aquellos Estados de la región que forman parte del Convenio núm. 169 de la Organización Internacional del Trabajo (V). Finalmente, el texto se cierra con la descripción del estado de la cuestión en la normativa legislativa y constitucional chilena, proponiendo como tesis el que esta última norma admite como lícito el ejercicio de la potestad expropiatoria a favor de un tercero, en este caso, indígena.

\section{EL DEBER ESTATAL DE REPARACIÓN POR DESPOSESIÓN}

Uno de los componentes no controvertidos del régimen de protección legal de las tierras indígenas consiste en el derecho a la reparación en caso que las comunidades se hayan visto privadas de la posesión de la misma. Este derecho, que forma parte del corpus general de remedios por la violación de derechos humanos ${ }^{1}$, ha sido codificado en el Convenio núm. 169 de la OIT (art. 14.3)² y es explícito, sin límite de tiempo, en la Declaración de Naciones sobre los Pueblos Indígenas (art. 28) ${ }^{3}$. En términos comparativos, el texto de la Declaración, que refiere genéricamente a la reparación y específicamente a la restitución y la compensación, es más preciso que el Convenio, que apela genéricamente a las "reivindicaciones" (revendications, en la versión francesa) o land claims (según la versión oficial inglesa) de la tierra desposeída.

\footnotetext{
${ }^{1}$ Véanse referencialmente los "Principios y directrices básicos sobre el derecho de las víctimas de violaciones manifiestas de las normas internacionales de derechos humanos y violaciones graves del derecho internacional humanitario a interponer recursos y obtener reparaciones", Asamblea General de Naciones Unidas, Resolución 60/147, 16 de diciembre de 2005. Sobre su contexto, génesis y sentido, véase Buyse Antoine, "Lost and Regained? Restitution as a Remedy for Human Rights Violations in the Context of International Law", en Zeitschrift für Auslandisches Öffentliches Recht und Völkerrecht 68 (2008), pp. 129-153, especialmente pp. 139 y ss. En material de reparación por desposesión de tierras, es todavía fundamental el estudio de Gilbert, Jérémie, Indigenous People's Land Rights under International Law. From Victims to Actors, Transnational Publ., Ardsley, 2006, pp. 141 y ss. Para una visión panorámica en materia de remedios, en general y de reparación en particular, la obra actualizada de referencia sigue siendo el libro de Shelton, Dinah, Remedies in International Human Rights Law, Oxford University Press, Oxford, 2015, tercera edición.

2 "Deberán instituirse procedimientos adecuados en el marco del sistema jurídico nacional para solucionar las reivindicaciones de tierras formuladas por los pueblos interesados”. Algunos comentaristas apuntan que esta referencia a las tierras desposeídas es solamente indirecta, Pentassuglia, Gaetano, "Towards a Jurisprudential Articulation of Indigenous Land Rights", en The European Journal of International Law 22/1 (2011), pp. 165-202, p. 168. Otros indican que "no resulta satisfactorio que el único requisito sobre la adjudicación de reclamos sea la existencia de 'procedimientos adecuados', debido sobre todo a la historia de abusos sobre los derechos de tierras indígenas", Mackay, Fergus, Los derechos de los pueblos indígenas en el sistema internacional, APRODEH, Lima, 1999, p. 156.

3 “1. Los pueblos indígenas tienen derecho a la reparación, por medios que pueden incluir la restitución o, cuando ello no sea posible, una indemnización justa y equitativa por las tierras, los territorios y los recursos que tradicionalmente hayan poseído u ocupado o utilizado y que hayan sido confiscados, tomados, ocupados, utilizados o dañados sin su consentimiento libre, previo e informado.

2. Salvo que los pueblos interesados hayan convenido libremente en otra cosa, la indemnización consistirá en tierras, territorios y recursos de igual calidad, extensión y condición jurídica o en una indemnización monetaria u otra reparación adecuada”.
} 
Como forma de remoción de los perjuicios causados por un acto injusto, la doctrina de la reparación se remonta a los criterios sostenidos por el célebre caso Fábrica de Chorzów de la Corte Permanente de Justicia Internacional (recogidos últimamente en la Opinión Consultiva de la Corte Internacional de Justicia en el caso del muro de Jerusalén) y se expresa seminalmente por la Corte IDH en el también notado caso Velásquez Rodríguez ("es un principio de Derecho internacional, que la jurisprudencia ha considerado incluso una concepción general de derecho', que toda violación a una obligación internacional que haya producido un daño comporta el deber de repararlo adecuadamente") ${ }^{4}$. Al interior del sistema de Naciones Unidas, este derecho ha sido desarrollado por el Comité para la Discriminación Racial (CERD, por sus siglas en inglés), en cuya Recomendación núm. XXIII (1997) se refiere explícitamente a la tierra indígena y "exhorta especialmente a los Estados Partes a que reconozcan y protejan los derechos de los pueblos indígenas a poseer, explotar, controlar y utilizar sus tierras, territorios y recursos comunales, y en los casos en que se les ha privado de sus tierras y territorios, de los que tradicionalmente eran dueños, o se han ocupado o utilizado esas tierras y territorios sin el consentimiento libre e informado de esos pueblos, que adopten medidas para que les sean devueltos. Únicamente cuando, por razones concretas, ello no sea posible, se sustituirá el derecho a la restitución por el derecho a una justa y pronta indemnización, la que, en la medida de lo posible, deberá ser en forma de tierras y territorios".

El deber de reparación ha sido recibido y desarrollado en la región por la CIDH y por la Corte IDH. Para ambas instituciones del sistema regional de derechos humanos, el derecho de propiedad tiene su fundamento en la ocupación y "la posesión de la tierra debe bastar para que las comunidades que carezcan de título real sobre la propiedad de la tierra obtengan reconocimiento oficial de dicha propiedad y el consiguiente registro" 5 . Para los órganos técnicos de la OIT, por su parte, "el establecimiento de los derechos de los pueblos indígenas sobre las tierras se basa en la ocupación y en el uso tradicional, y no en el eventual reconocimiento o registro legal oficial de la propiedad de la tierra por parte de los Estados, en virtud de que la ocupación tradicional confiere el "derecho a la tierra en virtud del Convenio, ... independientemente de que tal derecho hubiera sido reconocido o no [por el Estado]"6. Por otra parte, es fundamental tener en cuenta que de la pérdida de la posesión no se sigue la extinción del derecho de propiedad sobre la tierra. Resumiendo su doctrina, la $\mathrm{CIDH}$ ha señalado que "los pueblos indígenas o tribales que pierdan la posesión total o parcial de sus territorios, mantienen sus derechos

${ }^{4}$ Corte IDH, caso Velásquez Rodríguez v. Honduras. Reparaciones y Costas, sentencia de 21 de julio de 1989, párr. 25. Véase Corte Internacional de Justicia, Opinión consultiva sobre las consecuencias jurídicas de la construcción de un muro en el territorio palestino ocupado, 9 de julio de 2004, párr. 152-153.

${ }^{5}$ Corte IDH, caso Caso Comunidad Mayagna (Sumo) Awas Tingni v. Nicaragua. Fondo, reparaciones y costas, sentencia de 31 de agosto de 2001, párr.151. Puede consultarse con provecho una síntesis de la doctrina del sistema interamericano en $\mathrm{CIDH}$, Pueblos indígenas. Comunidades afrodescendientes. Industria extractiva. OEA/Ser. L./V/II, Doc. 47/15, 31 de diciembre de 2015, párr. 232 y ss.

${ }^{6}$ Véase OIT, CEACR, 73.a sesión, Observación, Perú, publicación 2003 (párrafo 7), citada en OIT, Departamento de Normas internacionales del Trabajo, Los derechos de los pueblos indígenas y tribales en la práctica. Una guía sobre el Convenio núm. 169 de la OIT, Ginebra, 2009, . 94. 
de propiedad sobre tales territorios, y tienen un derecho preferente a recuperarlos, incluso cuando se encuentren en manos de terceras personas. $\mathrm{La} \mathrm{CIDH}$ ha resaltado la necesidad de que los Estados tomen medidas orientadas a restaurar los derechos de los pueblos indígenas sobre sus territorios ancestrales, y ha indicado que la restitución de tierras es un derecho esencial para la supervivencia cultural y para mantener la integridad comunitaria. La CIDH, por su parte, considera que el derecho a la restitución de las tierras y territorios de los que los pueblos se han visto privados sin su consentimiento es uno de los principios internacionales relativos a los derechos de los pueblos indígenas sobre sus tierras, territorios y recursos naturales" 7 . En idéntico sentido, la Corte IDH ha insistido en que "los miembros de los pueblos indígenas que por causas ajenas a su voluntad han salido o perdido la posesión de sus tierras tradicionales mantienen el derecho de propiedad sobre las mismas, aun a falta de título legal, salvo cuando las tierras hayan sido legítimamente trasladadas a terceros de buena fe" 8 .

De acuerdo con el Derecho internacional, y sin perjuicio de lo que más adelante se dirá respecto de las desposesiones históricas, la pérdida de la posesión genera entonces para los afectados un derecho de restitución o recuperación que se traduce en el deber estatal de reintegro, sin perjuicio de las otras formas de reparación copulativas que admite el derecho internacional (rehabilitación, no repetición y las fórmulas satisfactivas no pecuniarias). Estas formas de reparación han sido tratadas por la literatura especializada dentro de las formas de reparación de injusticias históricas ${ }^{9}$ y han sido interpretadas por algunos como el asomo de una nueva forma de justicia transicional ${ }^{10}$. En todo caso, cualquiera que sea la visión que de estas formas de reparación se tenga, no escapan de ellas las exigencias de adecuación, integralidad y efectividad ${ }^{11}$. Como indica Martín, se trata de un proceso complejo, ya que "la reparación tiene que responder al sentir, necesidades y proceso de las víctimas, además de a las características de las violaciones

${ }^{7} \mathrm{CIDH}$, Derechos de los pueblos indígenas y tribales sobre sus tierras ancestrales y recursos naturales. Normas $y$ jurisprudencia del sistema interamericano, OEA/Ser. L./V/II, Doc. 56/09, 30 de diciembre de 2009, párr. 123. La doctrina y la labor compositiva de la CIDH en esta área ha sido comparada con el Tribunal de Waitangi, véase Gilbert, Jérémie, Indigenous People's Land Rights under International Law. From Victims to Actors, cit. nt. 2, p. 172.

8 Corte IDH, caso Comunidad Indígena Sawhoyamaxa v. Paraguay. Fondo, Reparaciones y Costas, sentencia de 29 de marzo de 2006, párr. 128. Véanse también, Corte IDH, caso Caso Comunidad indígena Yakye Axa v. Paraguay. Fondo, reparaciones y costas, sentencia de 17 de junio de 2005, párrs. 124 y ss.; caso de la Comunidad Moiwana, sentencia 15 de junio de 2005, párr. 134.

${ }^{9}$ Gómez Isa, Felipe, "El derecho de los pueblos indígenas a la reparación por injusticias históricas", en Álvarez, Natalia, Oliva, Daniel y Zúñiga, Nieves (Eds.), Declaración sobre los derechos de los pueblos indígenas. Hacia un mundo intercultural y sostenible, Catarata, Madrid, 2009, pp. 157-191.

${ }^{10}$ Jung, Courtney, "Canada and the Legacy of the Indian Residential Schools: Transitional Justice for Indigenous Peoples in a Nontransitional Society”, en Paige, Arthur (Ed.), Identities in Transition. Challenges for Transitional Justice in Divided Societies, Cambridge University Press, Cambridge, pp. 217-250.

${ }^{11}$ Lenzerini, Federico, "Reparations for Indigenous Peoples in International and Comparative Law", en Lenzerini, Federico (Ed.), Reparations for Indigenous Peoples. International \& Comparative Perspectives, Oxford University Press, Oxford, 2009, pp. 13-15. Sobre el derecho a la recuperación, véase la obra de Aylwin, José, Meza-Lopehandía, Matías y Yáñez, Los pueblos indígenas y el derecho, Lom, Santiago, 2013, pp. 494 y ss. 
o los aspectos jurídicos. Estas pueden matizar el valor atribuido a medidas concretas, como una medida simbólica, o una reparación económica; pero también tienen una dimensión más global que atraviesan los valores en que se basan las distintas medidas" 12 .

Es importante destacar que el deber de reparación no prescribe con el paso del tiempo. Como bien se sabe, en el campo de los derechos humanos la responsabilidad del Estado por graves violaciones a los derechos humanos no se extingue por ninguna modalidad de prescripción, principio que se explica tanto por la gravedad de la violación como por su carácter permanente o continuo en el tiempo ${ }^{13}$. Este principio general halla especial aplicación tratándose de remedios que favorecen a las poblaciones indígenas ${ }^{14}$ y particularmente respecto de las provisiones relativas a la propiedad. En efecto, como señala la doctrina autorizada, la disposición del art. 14.3 del Convenio 169 no tiene limitaciones temporales ${ }^{15}$, al igual que los principios recogidos en los artículos $27 \mathrm{y}$ 28 de la Declaración de Naciones Unidas sobre derechos de lo pueblos indígenas ${ }^{16}$. Sin perjuicio de lo anterior, como se explicará más adelante, el tiempo puede incidir afirmativamente en el modo en que la reparación se haga efectiva -por ejemplo, negando lugar a la restitución y reemplazándola por otro remedio lícito- cuando la desposesión tenga el carácter de vulneración o injusticia histórica.

\section{LA RESTITUTIO IN INTEGRUM COMO FORMA POSIBLE PERO NO EXCLUSIVA DE REPARACIÓN: LAS LIMITACIONES AL DERECHO A LA RESTITUCIÓN Y SUS OBJECIONES POLÍTICAS}

El derecho a la restitutio in integrum no es un derecho absoluto. Él puede derivar en un derecho a la compensación cuando aquella no sea posible en virtud de "razones concretas", como puede ser la radicación del inmueble en el patrimonio de terceros. Esta dimensión del derecho a la restitución es explicada por la Corte IDH en el caso de la Comunidad Sawhoyamaxa bajo el epígrafe limitación temporal del derecho de recuperación:

${ }^{12}$ Martín, Carlos, "Derecho a la reparación en los casos indígenas", en Gómez, Felipe y Berraondo, Mikel (Eds.), Los derechos indígenas tras la Declaración. El desafío de la implementación, Publicaciones de la Universidad de Deusto, Bilbao, 2013, pp. 334-335.

${ }^{13}$ Duffy, Aoife, “Indigenous Peoples' Land Rights: Developing a Sui Generis Approach to Ownership and Restitution", International Journal on Minority and Group Rights 15 (2008), pp. 505-538, p. 520.

${ }^{14}$ Acerca del problema del tiempo, véase Francioni, Francesco, "Reparation for Indigenous Peoples: Is International Law Ready to Ensure Reddress for Historical Injustices”, en Lenzerini, Federico (Ed.), Reparations for Indigenous Peoples. International E Comparative Perspectives, Oxford University Press, Oxford, 2009, pp. 42-44.

15 Anaya, James, Indigenous Peoples and International Law, Oxford University Press, New York, 2004, p. 144.

16 Pentassuglia, Gaetano, “Towards a Jurisprudential Articulation of Indigenous Land Rights”, cit. nt. 2, p. 169. 
"El segundo punto de análisis se refiere a si el derecho de recuperación de tierras tradicionales permanece indefinidamente en el tiempo. Para dilucidar este asunto, la Corte toma en cuenta que la base espiritual y material de la identidad de los pueblos indígenas se sustenta principalmente en su relación única con sus tierras tradicionales. Mientras esa relación exista, el derecho a la reivindicación permanecerá vigente, caso contrario, se extinguirá. Dicha relación puede expresarse de distintas maneras, según el pueblo indígena del que se trate y las circunstancias concretas en que se encuentre, y puede incluir el uso o presencia tradicional, ya sea a través de lazos espirituales o ceremoniales; asentamientos o cultivos esporádicos; caza, pesca o recolección estacional o nómada; uso de recursos naturales ligados a sus costumbres; y cualquier otro elemento característico de su cultura. (...) Debe considerase, además, que la relación con la tierra debe ser posible. Por ejemplo, en casos como el presente, que la relación con la tierra se manifiesta inter alia en las actividades tradicionales de caza, pesca y recolección, si los indígenas realizan pocas o ninguna de esas actividades tradicionales dentro de las tierras que han perdido, porque se han visto impedidos de hacerlo por causas ajenas a su voluntad que impliquen un obstáculo real de mantener dicha relación, como violencias o amenazas en su contra, se entenderá que el derecho a la recuperación persiste hasta que tales impedimentos desaparezcan"17.

En el caso de la Comunidad indígena Yakye Axa, la Corte IDH encuadró el interés por la restitución con otros intereses públicos concurrentes señalando que el primero no goza de preferencia sobre los segundos:

"Esto [la restricción de los derechos de propiedad privada para lograr el objetivo colectivo de preservar la identidad indígena] no significa que siempre que estén en conflicto los intereses territoriales particulares o estatales y los intereses territoriales de los miembros de las comunidades indígenas, prevalezcan los últimos por sobre los primeros. Cuando los Estados se vean imposibilitados, por razones concretas y justificadas, de adoptar medidas para devolver el territorio tradicional y los recursos comunales de las poblaciones indígenas, la compensación que se otorgue debe tener como orientación principal el significado que tiene la tierra para estas (...) (...)

La elección y entrega de tierras alternativas, el pago de una justa indemnización o ambos no quedan sujetas a criterios meramente discrecionales del Estado, deben ser, conforme a una interpretación integral del Convenio No. 169 de la OIT y de la Convención Americana, consensuadas con los pueblos interesados, conforme a sus propios procedimientos de consulta, valores, usos y derecho consuetudinario"18.

17 Corte IDH, caso Comunidad Indígena Sawhoyamaxa v. Paraguay. Fondo, Reparaciones y Costas, sentencia de 29 de marzo de 2006, párr. 131.

18 Corte IDH, caso Caso Comunidad indígena Yakye Axa v. Paraguay. Fondo, reparaciones y costas, sentencia de 17 de junio de 2005, párrs. 149 y 151. 
En su jurisprudencia más reciente, la Corte ha reiterado que la prevalencia de los derechos territoriales indígenas sobre los derechos de propiedad privada, al igual que el problema técnico de la demarcación de las tierras, no es una cuestión que deba ser resuelta por la Corte IDH. Estos asuntos son, para la Corte IDH, cuestiones de derecho interno ${ }^{19}$.

El carácter limitado del derecho a la restitución no está solamente refrendado en la jurisprudencia de la Corte IDH, los comentarios de la CIDH o del CERD, sino que emana expresamente del texto de la Declaración y del Convenio núm. 169. En efecto, este último, sujeta las "reivindicaciones" o land claims al marco regulatorio del "sistema jurídico nacional” (art. 14.3) y condiciona el retorno de las poblaciones trasladadas a que ello sea "posible”. En la lógica de consensos que caracterizó la negociación del Convenio núm. 169, estas últimas referencias surgieron como una forma de atender las demandas de restitución y, al mismo tiempo, promover un acuerdo internacional que no generase más resistencia entre los Estados miembros de la OIT. No muy distinta a esta fue la política de acuerdos que inspiró, en esta parte, el texto de la Declaración ${ }^{20}$. Por tanto, las mentadas fórmulas de consenso, interpretadas en consonancia con la cláusula de flexibilidad que obliga a tener en cuenta "las condiciones de cada país" (art. 34), configuran un derecho cuya estructuración ha quedado entregada al margen de apreciación estatal $^{21}$, sujeto en todo caso al ineludible deber de buena fe que inspira la interpretación

19 " $[\mathrm{L}] \mathrm{a}$ Corte reitera su jurisprudencia en la cual se establece que no puede decidir si el derecho a la propiedad tradicional de los miembros de una Comunidad indígena se encuentra por encima del derecho a la propiedad privada de terceros o viceversa, por cuanto la Corte no es un tribunal de derecho interno que dirime las controversias entre particulares. Esa tarea corresponde exclusivamente al Estado. No obstante, al Tribunal le compete analizar si el Estado garantizó o no los derechos humanos de la Comunidad indígena", Corte IDH, Caso de los pueblos Kuna de Madungandí y emberá de Bayano y sus miembros v. Panamá. Excepciones preliminares, fondo, reparaciones y costas, sentencia de 14 de octubre de 2014, párr. 144.

${ }^{20}$ Según Charters, en el proceso de redacción de la Declaración hubo una importante presión para que los pueblos indígenas pudiesen tener un derecho a la reparación como algo diverso del derecho a "perseguir" la reparación; por otra parte, sin embargo, "el texto refleja el compromiso para incluir una compensación que incluya 'otra reparación adecuada', lo que fue preferido por Estados conservadores tales como Australia, Nueva Zelanda y Estados Unidos”, Charters, Claire, "Reparations for Indigenous Peoples: Global International Instruments and Institutions”, en Lenzerini, Federico (Ed.), Reparations for Indigenous Peoples. International E Comparative Perspectives, cit. nt. 11, pp. 163-195, p. 171. En el mismo sentido, Pentassuglia, Gaetano, “Towards a Jurisprudential Articulation of Indigenous Land Rights”, cit. nt. 2, p. 168.

${ }^{21}$ A pesar de haber sido sugerido por los representantes trabajadores, el párrafo 3 del actual art. 14 no formó parte de la versión inicial de la reforma al Convenio núm. 107, véase Conferencia Internacional del Trabajo, Informe de la Comisión del Convenio núm. 107, Actas Provisionales, 75ª Reunión, Ginebra, 1988, pp. 32/16-17 y 32/28. En las actas de la segunda discusión se manifestó que "algunas respuestas sugieren que el presente artículo haga referencia al artículo 19 en lo que atañe a la solución de conflictos sobre reivindicaciones de tierras. La Oficina ha decidido incluir el artículo 19 en el artículo presente (artículo 14 del nuevo texto), reconociendo los estrechos vínculos existentes entre la determinación de las tierras pertinentes y la solución de conflictos sobre reivindicaciones. Se ha juzgado oportuno conservar la redacción existente en aras de la máxima flexibilidad". El texto que de aquí surgió fue el siguiente: "Deberán instituirse procedimientos adecuados, dentro del marco del ordenamiento jurídico nacional, para atender las reivindicaciones de tierras por parte de los (pueblos/poblaciones) interesados, incluidas las reivindicaciones fundadas en tratados"; la referencia a los tratados fue eliminada, aunque hay una referencia genérica a ellos en el actual art. 35 del Convenio; véase Conferencia Internacional del Trabajo, $76^{a}$ Reunión, Ginebra, 1989, 
y ejecución de las obligaciones internacionales de los Estados. En este sentido, y desde el punto de vista de la estructura dogmática de los derechos, la restitutio in integrum de las tierras desposeídas es la opción preferente y tendrá el carácter de derecho stricto sensu cuando se trata de desposesiones relativamente recientes en el tiempo (y, por tanto, no afectas al juicio acerca de la procedencia de otras formas de compensación) o, tratándose de desposesiones históricas, siempre que el Estado carezca de razones objetivas para preferir otras formas de compensación.

En el terreno práctico, los gobiernos ponderarán la factibilidad de la restitución tomando en cuenta diversas variables, entre estas figura en primer lugar la titularidad actual del dominio de las tierras reivindicadas. De tratarse de predios radicados en el patrimonio estatal o fiscal, el problema consistirá en determinar la posibilidad de transferirlos una vez que se haya ponderado el interés por mantener su uso actual (p. ej. bienes dedicados a una función o uso público) versus el interés de la comunidad reclamante. Por tanto, en el caso de terrenos fiscales baldíos, o no dedicados actualmente a un fin público, existirá una sólida presunción a favor de la restitución. En caso que se trate de un predio radicado en una persona diversa del Estado y que haya adquirido el predio de buena fe y con pleno cumplimiento de la normativa inmobiliaria especial, habrá que evaluar la posibilidad de obtener la transferencia voluntaria o, en su caso, forzosa por medio del ejercicio de la potestad expropiatoria. En esta última situación, surge una segunda variable muchísimo más compleja que la anterior, porque se trata de una decisión de carácter político que usualmente ponderará la satisfacción de más de un interés en conflicto. En efecto, el recurso a la expropiación suele ser problemático cuando existen otras formas de compensación o cuando no obedece a una política de Estado consensuada con los propios pueblos afectados y que admita que la restitución ideal o completa no es realista ni, en muchos casos, políticamente posible. El problema recién anotado no es exclusivo de la cuestión indígena sino que es propio de toda las expropiaciones con finalidad restitutoria. Si se examina la historia reciente chilena, es posible encontrar la sumisión a la misma fórmula de realidad en la legislación que dispuso la restitución o indemnizaciones por bienes confiscados en dictadura ${ }^{22}$, del mismo modo en que las sociedades europeas postcomunistas propiciaron limitadamente la restitución de bienes confiscados o en que algunas latinoamericanas han querido reparar los perjuicios sociales del conflicto armado. En todos estos casos, sobre las políticas de restitución pesará la acusación de generar víctimas de segunda categoría ${ }^{23}$ o simplemente de discriminar para dejar a parte de los perjudicados sin reparación ${ }^{24}$. Como recuerda Dinah Shelton, a

Informe IV ( $2^{\mathrm{a}}$ ), Revisión parcial del Convenio sobre poblaciones indígenas y tribales, 1957 (núm. 107), pp. 43 y 58. Acerca de la difícil discusión de la restitución en la revisión del Convenio 107, véase Gilbert, Jérémie, Indigenous People's Land Rights under International Law. From Victims to Actors, cit.nt. 2, pp. 154-157.

${ }^{22}$ Ley núm. 19.568, D. Of. de 23 de julio de 1998, art. 8; véase Lira, Elizabeth y Loveman, Brian, Políticas de reparación. Chile 1990-2004, Lom, Santiago de Chile, 2005, pp. 407 y ss.

${ }^{23}$ Kuti, Csongor, Post-Communist Restitution and the Rule of Law, Central Europe University Press, Budapest-New York, 2009, p. 289.

${ }^{24}$ Martínez, Paula, The Victims and Land Restitution Law in Colombia. An analysis of the contradictions between the agrarian model and compensation for the victims, FDCL, Berlín, 2013, pp. 13 y ss. 
pesar que el derecho se encuentre claramente justificado por la confiscación, "podría ser inequitativo o impracticable transferir la propiedad de regreso al propietario original" 25 . Posiblemente por todo esto es que una ex autoridad de gobierno en la Araucanía se declaró, a los pocos meses de asumido en el cargo, contraria a una política de expropiaciones ${ }^{26}$.

Esta faz problemática de las expropiaciones restaurativas desborda el discurso puramente legal y alcanza también el de la teoría política. En este último ámbito se han formulado objeciones que aquí solo se pueden esbozar. En efecto, o se critica el carácter necesariamente incompleto $-y$, por tanto, discriminatorio- de los diseños legales de reparación o se las acusa de ser una fuente potencial de nuevas injusticias presentes para remediar las injusticias del pasado. En esta línea de argumentación se inscriben los aportes de Gregory Alexander o de Jeremy Waldron. Sin trivializar o negar las injusticias históricas, ambos autores comparten la necesidad de ponderar el efecto del tiempo en la satisfacción de las demandas de restitución y expresan sus dudas respecto de la plena justificación ética y política de las mismas. El primero ha puesto el énfasis en los "errores cognitivos" que se esconden tras la valoración de la causalidad que explica las políticas de reparación y en aquello que identifica con el "principio de rectificación”, según este último principio, la justificación moral para la protección de ciertas titularidades reside en el rol que ellas juegan en la vida de la persona. Según Alexander, el paso del tiempo necesariamente erosiona la aplicación de este principio ${ }^{27}$. Waldron, por su parte, se resiste a aislar las demandas de reivindicación de sus circunstancias de justificación. Él sostiene, al igual que Alexander, que los derechos no son inmunes al paso del tiempo y se pregunta si los cambios de circunstancias no afectan acaso la justificación de los mismos: “está la justicia relacionada con las circunstancias? ¿Cambian los derechos si las circunstancias cambian? ¿O simplemente debemos decir que una vez que algo se hace mío permanece así (y, por tanto, es injusto que te apropies de ello) sin que importe qué más suceda en el mundo?"28.

\section{EXPROPIACIONES RESTITUTORIAS Y PROPIEDAD INDÍGENA: DOCTRINA Y JURISPRUDENCIA INTERNACIONAL}

La doctrina de los organismos internacionales de derechos humanos no descarta a priori la posibilidad de recurrir a la expropiación como instrumento para recuperar tierras demandadas por comunidades indígenas. Muy por el contrario, además de ser un

25 Shelton, Dinah, Remedies in International Human Rights Law, cit. nt. 1, p. 304.

${ }^{26}$ Véase la entrevista al ex-Intendente de la IX Región, el abogado Francisco Huenchumilla, en $L a$ Tercera, 19 de julio de 2014, p. 2. "No soy partidario de una ley de expropiaciones. Creo que eso significaría crear otro problema político. No sería conveniente”.

27 Alexander, Gregory, “The Limits of Property Reparations”, en Cornell Law School Legal Studies Research Papers 5 (2004), pp. 4 y ss.

${ }^{28}$ Waldron, Jeremy, “Superseding Historic Injustice”, en Ethics 103/1 (1992), pp. 4-28, p. 26. 
método expresamente admitido por los órganos de supervisión del Convenio núm. 16929, la expropiación para radicar la tierra en comunidades indígenas ha sido expresamente admitida por la Corte IDH y la CIDH. Remitiéndose a la doctrina del caso Sawhoyamaxa, la $\mathrm{CIDH}$ ha manifestado que la expropiación incluso es procedente si el propietario privado está amparado por algún acuerdo internacional de protección de inversiones:

“[D]ebe recordarse que, según la Corte Interamericana, la existencia de tratados internacionales bilaterales de inversión en vigor que protejan a los propietarios de las tierras reclamadas no justifica la falta de concreción o materialización del derecho a la propiedad y recuperación territorial de los pueblos indígenas y tribales, porque la implementación de los tratados comerciales bilaterales debe hacerse compatible con la Convención Americana, mucho más si contienen cláusulas que permiten la expropiación de las inversiones de nacionales de una de las partes contratantes por causa de utilidad o interés público, 'lo cual podría justificar la devolución de tierras a los indígenas'. Para la Corte Interamericana, la aplicación de los tratados comerciales bilaterales 'debe ser siempre compatible con la Convención Americana, tratado multilateral de derechos humanos dotado de especificidad propia, que genera derechos a favor de individuos y no depende enteramente de la reciprocidad de los Estados'" 30 .

Por cuanto se refiere a la jurisprudencia contenciosa de la Corte, puede sostenerse con entera certeza que la admisibilidad de la expropiación como vehículo para constitución del dominio indígena - con el correspondiente reconocimiento del margen de apreciación estatal- es doctrina constante de la Corte IDH. En efecto, el ejercicio de la potestad expropiatoria es explícitamente reconocida como una vía lícita para los gobiernos en los casos Yakye Axa $(2005)^{31}$, Sawhoyamaxa (2006) ${ }^{32}$, Xákmok Kásek

${ }^{29}$ Sin perjuicio de no formar parte del mandato de los órganos de la OIT, véanse, a título ejemplar, las opiniones del CEACR: Solicitud directa, adopción: 2008, publ.: 98 ${ }^{\text {a }}$ Reunión CIT (2009), Paraguay; Solicitud directa, adopción: 2013, publ.: $103^{\mathrm{a}}$ Reunión CIT (2014), México; y Solicitud directa, adopción: 2014, publ.: 104ª Reunión CIT (2015), Paraguay.

${ }^{30} \mathrm{CIDH}$, Derechos de los pueblos indígenas y tribales sobre sus tierras ancestrales y recursos naturales. Normas y jurisprudencia del sistema interamericano, cit. nt. 5, párr. 121.

31 Corte IDH, caso Caso Comunidad indígena Yakye Axa v. Paraguay. Fondo, reparaciones y costas, sentencia de 17 de junio de 2005, párrs 217, "[e]n caso de que el territorio tradicional se encuentre en manos privadas, el Estado deberá valorar la legalidad, necesidad y proporcionalidad de la expropiación o no de esas tierras con el fin de lograr un objetivo legítimo en una sociedad democrática".

${ }^{32}$ Comunidad Indígena Sawhoyamaxa v. Paraguay. Fondo, Reparaciones y Costas, sentencia de 29 de marzo de 2006, párr. 215: "El Estado cuenta con un plazo de tres años, contado a partir de la notificación de la presente Sentencia, para entregar las tierras física y formalmente a las víctimas, sea que se adquieran por medio de compra, expropiación o elección de tierras alternativas. Para ello, deberá asegurar todos los fondos necesarios". 
$(2010)^{33}$ y en los más recientes fallos de los pueblos KalinalLokono (2015) 34 y Comunidad Garífuna de Punta Piedra (2015) ${ }^{35}$. La doctrina de estos fallos es consistente en señalar que la apropiación privada no descarta necesariamente la restitución, como tampoco el

33 Corte IDH, caso Comunidad Indígena Xákmok Kásek v. Paraguay. Fondo, reparaciones y costas, sentencia de 24 de agosto de 2010, párrs 284 y ss.: "Una vez identificado plenamente el territorio tradicional de los miembros de la Comunidad, de la forma y en el plazo señalados en el párrafo anterior, de encontrarse este en manos de particulares, sean estos personas naturales o jurídicas, el Estado deberá, a través de sus autoridades competentes, decidir si procede la expropiación del territorio a favor de los indígenas. Para resolver esta cuestión, las autoridades estatales deben seguir los estándares establecidos en esta Sentencia (...), teniendo muy en cuenta la especial relación que los indígenas tienen con sus tierras para la preservación de su cultura y su supervivencia. En ningún caso la decisión de las autoridades internas deberá basarse exclusivamente en que dichas tierras estén en manos privadas o que estén racionalmente explotadas, por las consideraciones expuestas en el párrafo 149 de esta Sentencia. Hacerlo sería desconocer la presente decisión y una violación a los compromisos adquiridos soberanamente por el Paraguay. (...). 286. Si por motivos objetivos y fundamentados -entre los cuales, se reitera, no podrán argüirse exclusivamente el hecho que las tierras estén en manos privadas o estén racionalmente explotadas- las autoridades paraguayas resuelven dar prioridad al derecho a la propiedad de los particulares por sobre el derecho a la propiedad de los miembros de la Comunidad, deberá entregar a estos tierras alternativas, dentro del territorio tradicional de sus ancestros. La elección de estas tierras deberá ser consensuada con los miembros de la Comunidad, de conformidad con sus propias formas de toma de decisiones. Se reitera que el ofrecimiento de tierras alternativas únicamente será procedente una vez que se haya valorado adecuadamente, conforme a lo indicado en esta Sentencia, que no es procedente la expropiación y que no se hayan concretado las negociaciones para la compra de las tierras".

${ }^{34}$ Corte IDH, caso Pueblos Kaliña y Lokono v. Surinam. Fondo, reparaciones y costas, sentencia de 29 de noviembre de 2015, párr. 158 y 280 y ss.: “158. Lo anteriormente señalado, no significa que siempre que estén en conflicto los intereses territoriales particulares o estatales y los intereses territoriales de los miembros de las comunidades indígenas, prevalezcan los últimos por sobre los primeros. Por ello, si el Estado se ve imposibilitado, por razones objetivas, concretas y justificadas de adoptar medidas para devolver el territorio tradicional y los recursos comunales a los Pueblos Kaliña y Lokono, luego de que se haya valorado adecuadamente conforme a lo indicado en esta Sentencia la posibilidad de expropiación de los territorios de terceros, podrá el Estado ofrecer tierras alternativas de igual o mayor extensión y calidad, el pago de una justa indemnización o ambos y de manera consensuada con los pueblos interesados” (...) "280. En el caso de que las tierras reclamadas en manos de terceros no indígenas ni tribales sean de personas naturales o jurídicas, el Estado deberá, a través de sus autoridades competentes, decidir si procede la compra o expropiación del territorio a favor de los indígenas, a través del pago de las indemnizaciones que corresponda a los perjudicados, de conformidad con lo establecido en el derecho interno. Para resolver esta cuestión, las autoridades estatales deben seguir los estándares establecidos en esta Sentencia (...), teniendo muy en cuenta la especial relación que los indígenas tienen con sus tierras para la preservación de su cultura y su supervivencia. En ningún caso la decisión de las autoridades internas deberá basarse exclusivamente en que dichas tierras estén en manos privadas o que estén racionalmente explotadas. 281. En el caso que, por motivos objetivos y debidamente fundados, el Estado considere que no es posible llevar a cabo la titulación de las tierras tradicionales, deberá conferir títulos de propiedad colectiva a dichos pueblos sobre tierras alternativas contiguas de igual extensión y calidad que las no otorgadas. El Estado, para la implementación de esta medida, deberá, contar con la participación efectiva de los Pueblos Kaliña y Lokono y sus miembros, de conformidad con los estándares en la materia”.

35 Corte IDH, caso Comunidad Garífuna de Punta Piedra y sus miembros vs. Honduras. Excepciones preliminares, fondo, reparaciones y costas, sentencia de 8 de octubre de 2015, párr. 324: "en el supuesto que se acredite la existencia de títulos legítimos de propiedad en la Aldea de Río Miel, anteriores a la entrega del segundo título a la Comunidad de Punta Piedra, conforme a la jurisprudencia de la Corte, el Estado deberá valorar la posibilidad de su compra o la expropiación de esas tierras, por razones de utilidad pública o interés social". 
que la tierra esté actualmente explotada o afecta a una declaración de área protegida. Teniendo en cuenta estas premisas, el Estado debe procurar la restitución, recurriendo si es necesario a la expropiación y dejando a salvo la posibilidad de rehuirla si hay motivos objetivos y fundados o si claramente la medida expropiatoria resulta, a su turno, innecesaria o desproporcionada (en esta última parte la Corte no hace sino aplicar los estándares generales en materia de restricciones a la propiedad). Este deber es bien explicado por la Corte IDH en el fallo interpretativo del caso Yakye Axa, ocasión en que la Corte identifica la ponderación de la expropiación como un deber de parte de los órganos responsables del Estado:

“[E]l Tribunal deja establecido con claridad que la tarea de identificar el territorio tradicional de la Comunidad Yakye Axa corresponde al Paraguay. No obstante, dicha labor deberá atenerse a lo dispuesto en la sentencia del Tribunal, en el sentido de que deberá tomar muy en cuenta los valores, usos, costumbres y derecho consuetudinario de los miembros de la Comunidad, que los ligan a un territorio determinado. Asimismo, en lo que respecta a la entrega de dicho territorio, de darse el caso que luego del proceso de identificación se desprenda que se encuentra en manos privadas, el Estado deberá valorar la conveniencia de la expropiación del mismo, teniendo en cuenta la especial significación que este tiene para la Comunidad. Finalmente, de darse motivos objetivos y fundamentados que imposibiliten que el Estado reivindique el territorio identificado como el tradicional de la Comunidad, deberá entregarle tierras alternativas, que serán electas de manera consensuada. En cualquiera de los casos, conforme se desprende del párrafo 217 de la Sentencia de fondo, 'la extensión de las tierras deberá ser la suficiente para garantizar el mantenimiento y desarrollo de la propia forma de vida de la Comunidad' "36.

En síntesis, la circunstancia de hallarse la tierra en dominio privado no genera automáticamente un deber estatal de adquirir la tierra vía expropiación sino más bien la obligación estatal de estudiar su factibilidad atendiendo a los principios y procedimientos generales (legalidad, necesidad y proporcionalidad). Si de ese proceso de evaluación resulta una decisión adversa a la restitución in integrum, ella debe ser fundamentada en motivos objetivos. Aunque la Corte IDH no lo indica expresamente, dichos procedimientos y sus razonamientos deberían ser públicos. Como indican los comentaristas, las restricciones a los derechos vinculados a la tierra deben discutirse de manera abierta, de modo tal que los conflictos de demandas e intereses puedan ser "ventilados en público" ${ }^{37}$.

Por tanto, en este esquema de ideas, de la desposesión se genera en primer lugar un derecho para que la demanda de restitución sea revisada por un órgano del Estado dotado

${ }^{36}$ Corte IDH, caso Caso Comunidad indígena Yakye Axa v. Paraguay. Interpretación de la sentencia de fondo, reparaciones y costas, sentencia de 6 de febrero de 2006, párr. 26, cursivas añadidas.

37 Swepston, Lee, "A New Step in the International Law on Indigenous and Tribal Peoples: ILO Convention No. 169 of 1989”, en Anaya, James (Ed.), International Law and Indigenous Peoples, Ashgate/ Darmouth, Aldershot, 2003, pp. 329-366, p. 350. 
de la competencia para resolver respecto del procedimiento que permita la devolución o, en su caso, la compensación alternativa mediante la entrega de otras tierras. Este órgano será usualmente de carácter administrativo y seguirá, de ordinario, a los procedimientos judiciales cuando estos no sean suficientes o idóneos para atender las demandas de restitución en caso que las tierras estén radicadas en el patrimonio de un tercer poseedor.

\section{EXPROPIACIONES RESTITUTORIAS EN LA LEGISLACIÓN REGIONAL}

A pesar de las dificultades arriba esbozadas es posible observar en los países de la región que forman parte del Convenio $\mathrm{N}^{\circ} 169$ diversos modos de recurrir a la expropiación como vía de constitución de la propiedad indígena o, a la inversa, de ejercicio de la potestad expropiatoria como forma de separación de la tierra respecto de sus titulares indígenas. Para efectos de esta investigación se identifica solo la legislación del primer tipo y se toma como muestra el grupo de países del continente que forman parte del Convenio $\mathrm{N}^{\circ}$ 169. Una mirada no exhaustiva a esta legislación muestra cierta tendencia a favor del instituto expropiatorio como una vía institucional de adquisición de tierras destinadas a satisfacer demandas de comunidades indígenas. En este levantamiento formal de legislación positiva, que no prejuzga acerca de la calidad ni la intensidad de su aplicación, se observa la formalización de la expropiación ya sea como potestad propia de la legislación agraria general o de la legislación indígena en particular.

En Centroamérica y México (ver Tabla núm. 1), junto con los instrumentos generales de política agraria ${ }^{38}$, se observan dos modalidades de legislación indígena especializada. O la legislación aborda el problema sin identificar una población particular (legislación expropiatoria especial-general, como acontece en Costa Rica) o bien ella se refiere a un grupo determinado de comunidades o a un área específica del territorio (legislación expropiatoria especial-especial).

${ }^{38}$ Acerca de reformas agrarias en la región y pueblos indígenas, Aylwin, José, El derecho de los pueblos indígenas a la tierra y al territorio en América Latina: Antecedentes históricos y tendencias actuales, OEA, véase pp. 5-6. Disponible en: http://www.archivochile.com/Ideas_Autores/aylwino_j/aylwinoj0002.pdf 
Tabla núm. 1. México y Centroamérica

\begin{tabular}{ccc}
\hline $\begin{array}{c}\text { País miembro } \\
\text { del Convenio } \\
\text { núm. } 169\end{array}$ & $\begin{array}{c}\text { Expropiación } \\
\text { por legislación general }\end{array}$ & $\begin{array}{c}\text { Expropiación } \\
\text { por legislación específica }\end{array}$ \\
\hline
\end{tabular}

Costa Rica

Ley núm. 6.172, 20 de diciembre de 1977, Ley indígena ${ }^{39}$.

$\begin{array}{ll}\text { Guatemala } & \text { Decreto núm. 1551, } 7 \text { de noviembre de } \\ & \text { 1962, Ley de Transformación agraria. }\end{array}$

Honduras Decreto núm. 82, 15 de junio de 2004,

Ley de propiedad.

México $^{40} \quad$ Ley agraria, 26 de febrero de $1992 . \quad *$

Nicaragua Decreto núm. 782, 19 de julio de 1981, Ley núm. 445, 13 de diciembre de 2002, Ley Ley de Reforma Agraria. de régimen comunal de los pueblos indígenas y comunidades étinicas de las regiones autónomas de la costa atlántica de Nicaragua y de los ríos Bocay, Coco, Indio y Maíz ${ }^{41}$.

En el grupo sudamericano (ver Tabla núm. 2) se observan los mismos patrones de la zona México-centroamericana, con dos peculiaridades. Por una parte, se observan Estados que no poseen legislación habilitante para la expropiación agraria o indígena (Chile) y Estados con profusión de leyes especiales para territorios determinados (leyes

${ }^{39} \mathrm{El}$ art. $5^{\circ}$ de esta ley dispone que "En el caso de personas no indígenas que sean propietarias o poseedoras de buena fe dentro de las reservas indígenas, el ITCO [Instituto de Tierras y Colonización] deberá reubicarlas en otras tierras similares, si ellas lo desearen; si no fuere posible reubicarlas o ellas no aceptaren la reubicación, deberá expropiarlas e indemnizarlas conforme a los procedimientos establecidos en la Ley n. ${ }^{\circ} 2825$ de 14 de octubre de 1961 y sus reformas. Los estudios y trámites de expropiación e indemnización serán efectuados por el ITCO en coordinación con la CONAI [Comisión Nacional de Asuntos Indígenas]”.

${ }^{40}$ México ha sido cuestionado por los órganos de la OIT, véase CEACR Observación, 2009, Publicación 99 Reunión CIT (2010): “Al tiempo que la Comisión toma nota de estos desarrollos, no puede dejar de expresar su preocupación por el hecho de que, aunque se reinstauren los procedimientos de Reconocimiento y Titulación de Bienes Comunales, queda el obstáculo de que, según se desprende de las alegaciones, no se dispone de un procedimiento adecuado que permita solucionar las reivindicaciones de tierras en conformidad con el Convenio. La Comisión señala nuevamente a la atención del gobierno que ya con respecto a la aplicación del Convenio sobre poblaciones indígenas y tribuales, 1957 (núm. 107), la Comisión había subrayado que la ocupación tradicional confiere el derecho a la tierra en virtud del Convenio, independientemente de que tal derecho se hubiera reconocido o no. De modo parecido, el artículo 14 del Convenio núm. 169 establece que la 'ocupación tradicional' es, en sí misma, fuente de derechos. Esto significa que si no se posibilita la resolución de reivindicaciones de tierras demostrando la ocupación tradicional, se podrían vulnerar los derechos a la tierra de los pueblos indígenas".

${ }^{41}$ Esta ley resguarda el derecho de terceros sobre tierras indígenas, a excepción de quien las hubiese adquirido con algún tipo de vicio. En este último caso, "El tercero que ha recibido título agrario con algún vicio de forma o de fondo en tierras indígenas, será indemnizado para que devuelva las tierras a las comunidades indígenas afectadas" (art. 37). 
especiales-especiales). Este último es el caso de Argentina, que ofrece diversos ejemplos de legislación federal que declara la utilidad pública de territorios situados en las provincias de Salta y Jujuy. A esta legislación hay que sumar aquella normativa provincial de adhesión a la federal, que en el caso de la Ley federal $\mathrm{N}^{\circ} 23.302$, ha promovido la expropiación de extensos territorios en la zona central del país. El ejemplo notable de esto último es la Ley $\mathrm{N}^{\circ}$ 6.920, aprobada por la legislatura de Mendoza el 9 de octubre de 2001 y que declaró de utilidad pública y sujeta a expropiación "la fracción de terreno que se encuentra comprendida entre los límites y demás circunstancias que se detallan en el anexo i y descripción de los titulares registrales que se detallan en el anexo ii, los que deberán acreditar mejor derecho, en el caso de superposición de títulos”. Esta ley fue luego impugnada por la Fiscalía del Estado ante la Suprema Corte de Justicia de Mendoza por su supuesto carácter desproporcionado, ya que la superficie a expropiar comprendía, aproximadamente, el $75 \%$ de la superficie de todo el departamento de Lavalle ${ }^{42}$.

Junto con la legislación expropiatoria particular argentina y su experiencia litigiosa es interesante observar el caso paraguayo. En este último país la Constitución de 1992 ("se admite la expropiación por causa de utilidad pública o de interés social, que será determinada en cada caso por ley”, art. 109) parece propiciar una interpretación a favor de las leyes expropiatorias particulares. Ello explica que las leyes expropiatorias con fines de regularización o de reforma agraria (particularmente a favor del Instituto Nacional de Desarrollo Rural y de la Tierra) no sean escasas y que hayan sido el camino escogido por el gobierno para cumplir con la sentencia del Caso Sawhoyamaxa. Al igual que aconteció con la ley mendocina, la Ley N 5.194 de 2014 (que declaró de interés social y expropió dos fincas de propiedad de empresas extranjeras) fue impugnada sin éxito ante la Sala Constitucional de la Corte Suprema ${ }^{43}$.

${ }^{42} \mathrm{La}$ acción de inconstitucionalidad fue rechazada, añadiendo la Corte que "es privativo de los poderes autores de la legislación el ponderar adecuadamente cuál es la extensión apropiada para cumplir los fines de utilidad pública que inspiran el dictado de la ley. No corresponde al Poder Judicial, en principio, interferir en el ejercicio de las facultades discrecionales que la Constitución y la ley han atribuido a los otros poderes del Estado. Únicamente en el exceso evidente, debidamente demostrado a través de los medios probatorios a su disposición, este Poder Judicial podría establecer la presencia de algunos de los vicios propios de la actividad discrecional como son la irracionabilidad y la desviación de poder. Es decir, la desproporción o la persecución de otros fines distintos a los que inspiraron el dictado de la ley", Corte Suprema de Justicia de Mendoza, 18 de diciembre de 2008, párr. III.4.

43 Esta acción de inconstitucionalidad fue rechazada en un breve fallo que remite la fundamentación al cumplimiento de lo resuelto por la Corte IDH y atendido que "se trata de reivindicaciones de larga data de comunidades indígenas, cuyos derechos han quedado persistentemente de un modo u otro resignados, y advirtiendo la injusticia extrema que significaría un nuevo prolongamiento en el caso", Corte Suprema de Paraguay, acuerdo y sentencia núm. 981, 30 de septiembre de 2014, acción de inconstitucionalidad "Kansol S.A. y Roswell Co. S.A. c. Ley núm. 5.194 que declara de interés social y expropia a favor del Instituto Paraguayo del Indígena”, párr. 9.1. 
Cuadro 2. Sudamérica

\begin{tabular}{lcc}
\hline País miembro del & Expropiación por & Expropiación por \\
Convenio $\mathrm{N}^{\circ} 169$ & legislación general & legislación específica \\
\hline
\end{tabular}

Argentina

Ley núm. 23.302, 30 de septiembre de 1985 , sobre política indígena y apoyo a las comunidades aborígenes ${ }^{44}$. Ley núm. 24.242, 6 de octubre de 1993 y 24.725, 23 de octubre de 1993.

Ley núm. 24.242, 25 de septiembre de 1992, declara de utilidad pública y sujeta a expropiación las tierras del Departamento de Oran, Salta, para aborígenes del pueblo Kolla; Ley núm. 24.334, 1 de julio de 1994, , declara de utilidad pública y sujeta a expropiación las tierras del Departamento de Iruya, Salta; Ley núm. 24.725, 15 de noviembre de 1996, declara de utilidad pública y sujeta a expropiación inmueble denominado Finca Tumbaya, en Departamento Tumbaya de Jujuy; Ley núm. 25.549, 27 de diciembre de 2001, declara de utilidad pública y sujeta a expropiación las tierras de Lapacho Mocho, Provincia de Salta.

\begin{tabular}{|c|c|}
\hline Bolivia & $\begin{array}{l}\text { Ley núm. } 3.345 \text {, de } 28 \text { de noviembre } \\
\text { de } 2006 \text {, de reconducción comunita- } \\
\text { ria de la reforma agraria y Ley núm. } \\
1.715 \text {, de } 18 \text { de octubre de } 1996, \\
\text { sobre el Servicio Nacional de Reforma } \\
\text { Agraria }{ }^{45} \text {. }\end{array}$ \\
\hline
\end{tabular}

${ }^{44} \mathrm{El}$ art. $8^{\circ}$ de esta Ley dispone: "La autoridad de aplicación elaborará, al efecto, planes de adjudicación y explotación de las tierras conforme a las disposiciones de la presente ley y de las leyes específicas vigentes sobre el particular, de modo de efectuar sin demora la adjudicación a los beneficiarios de tierras fiscales de propiedad de la Nación. El Poder Ejecutivo dispondrá la transferencia de las tierras afectadas a esos fines a la autoridad de aplicación para el otorgamiento de la posesión y posteriormente de los títulos respectivos. Si en el lugar de emplazamiento de la comunidad no hubiese tierras fiscales de propiedad de la Nación, aptas o disponibles, se gestionará la transferencia de tierras fiscales de propiedad provincial y comunal para los fines indicados o su adjudicación directa por el gobierno de la provincia o en su caso, el municipal. Si fuese necesario la autoridad de aplicación propondrá la expropiación de tierras de propiedad privada al Poder Ejecutivo, el que promoverá ante el Congreso Nacional las leyes necesarias”...

45 Esta es la legislación que ha aplicado el gobierno del presidente Morales para conceder títulos de propiedad a las comunidades indígenas guaraníes (180.000 hectáreas) del departamento de Chuquisaca. 


\begin{tabular}{|c|c|c|}
\hline $\begin{array}{l}\text { País miembro del } \\
\text { Convenio } \mathrm{N}^{\circ} 169\end{array}$ & $\begin{array}{l}\text { Expropiación por } \\
\text { legislación general }\end{array}$ & $\begin{array}{l}\text { Expropiación por } \\
\text { legislación específica }\end{array}$ \\
\hline Brasil & $\begin{array}{l}\text { Ley núm. } 4.132 \text {, de } 10 \text { de septiembre } \\
\text { de } 1962 \text {, define os casos de desapro- } \\
\text { priação e dispõe sobre sua aplicação } \\
\text { y Decreto Lei núm. } 3.365 \text { de } 21 \text { de } \\
\text { junio de } 1941^{46} \text {. }\end{array}$ & \\
\hline Chile & $*$ & $*$ \\
\hline Colombia & $\begin{array}{l}\text { Ley núm. } 160,5 \text { de agosto de } 1994 \text {, } \\
\text { crea el Sistema Nacional de Re- } \\
\text { forma Agraria y Desarrollo Rural } \\
\text { Campesino. }\end{array}$ & $\begin{array}{l}\text { Decreto núm. 359, } 30 \text { de septiembre de } \\
\text { 2009, Ministerio de Agricultura y Desa- } \\
\text { rrollo Rural, aprueba a modificación de } \\
\text { la estructura del Instituto Colombiano } \\
\text { de Desarrollo Rural INCODER }{ }^{47} \text {. }\end{array}$ \\
\hline Ecuador & $\begin{array}{l}\text { Ley núm. 54, } 2 \text { de junio de 1994, de } \\
\text { Desarrollo Agrario }\end{array}$ & \\
\hline Paraguay & $\begin{array}{l}\text { Ley núm. } 1.863 \text { de 2002, Estatuto } \\
\text { Agrario }\end{array}$ & $\begin{array}{l}\text { Ley núm. } 904 \text {, estatuto de las comuni- } \\
\text { dades indígenas y Ley núm. 5.194, } 11 \\
\text { de junio de } 2014^{48} \text {. }\end{array}$ \\
\hline Perú & & $\begin{array}{l}\text { Decreto Ley núm. } 22.175,9 \text { de mayo } \\
\text { de } 1978 \text {, Ley de comunidades nativas y } \\
\text { desarrollo agrario de las regiones de selva } \\
\text { y cejas de selva }{ }^{49} \text { y Ley núm. } 24.657,13 \\
\text { de abril de } 1987 \text {, declara de necesidad } \\
\text { nacional e interés social el deslinde y la } \\
\text { titulación del territorio de las comuni- } \\
\text { dades campesinas. }\end{array}$ \\
\hline
\end{tabular}

${ }^{46}$ Esta Lei ha sido recientemente utilizada por el gobierno de la presidenta Rousseff para regularizar el territorio Quilombola de Alto Alegre y Adyacencia, en el estado de Ceará.

${ }^{47}$ Este decreto fue modificado por el Decreto núm. 2365 de 2015, que suprimió el INCODER y dispuso su liquidación. Entre las facultades del INCODER figuraba "adquirir y expropiar tierras y mejoras para dotar a las comunidades negras e indígenas, deslindar y clarificar las tierras de estas comunidades". Véase la sentencia de la Corte Constitucional C-175 de 18 de marzo de 2009.

${ }^{48}$ Esta ley se dictó para cumplir con el fallo del caso Comunidad Indígena Sawboyamaxa v. Paraguay. Fondo, Reparaciones y Costas, sentencia de 29 de marzo de 2006, párr. 215, cit. nt. 8.

${ }^{49}$ Esta ley, art. $12^{\circ}$, permite al Estado incorporar, previa compensación, al territorio de las comunidades las tierras ubicadas dentro de su perímetro y que hayan sido adjudicadas por el Estado a particulares. 


\begin{tabular}{ccc}
\hline País miembro del & Expropiación por & Expropiación por \\
Convenio núm. 169 & legislación general & legislación específica \\
\hline
\end{tabular}

Venezuela

Decreto núm. 1.546, 9 de noviembre de 2001, Ley de Tierras y Desarrollo Agrario. Ley de demarcación y garantía del hábitat y tierras de los pueblos indígenas, 12 de enero de 2001. Ley orgánica de pueblos y comunidades indígenas, 27 de diciembre de $2005^{50}$.

\section{LA CONSTITUCIÓN DE LA PROPIEDAD INDÍGENA COMO FIN DE LA EXPROPIACIÓN EN LA LEGISLACIÓN CHILENA}

Como se sugirió anteriormente, la legislación chilena vigente carece de habilitaciones legales específicas que permitan la expropiación para radicar la tierra en el patrimonio de comunidades indígenas. A pesar de las recomendaciones de la Comisión Verdad Histórica y Nuevo Trato con los Pueblos Indígenas ${ }^{51}$, del Instituto Nacional de Derechos Humanos $^{52}$ o de algunos relatores de Naciones Unidas ${ }^{53}$, el Estado chileno ha optado por

${ }^{50}$ Esta ley, como tampoco la de demarcación, no contempla expresamente la posibilidad de expropiar, sin embargo sí reconoce una suerte de derecho de restitución condicional. Su art. 24 reza del siguiente modo: "Los pueblos y comunidades indígenas que por medios violentos o vías de hecho hayan sido desplazados de su hábitat y tierras, o por razones de seguridad se hayan visto forzados a ocupar otras, tienen derecho a la restitución de su hábitat y tierras originarios o, en su defecto, a la demarcación y titulación de aquellos que actualmente ocupan, preferiblemente en áreas aledañas al hábitat y tierras indígenas originarias.

Cuando no proceda la restitución o la demarcación a que se contrae el presente artículo, el Estado garantizará a los pueblos y comunidades indígenas el derecho a tierras de similares condiciones a las del hábitat y tierras originarias y que atiendan a las necesidades y expectativas de los pueblos y comunidades indígenas involucrados, conforme a las leyes que rigen la materia.

Estas tierras serán inalienables, imprescriptibles, inembargables e intransferibles”.

51 "[E]s opinión de la Comisión que debe procederse a la expropiación de las tierras correspondientes, para lo cual, una vez concluido el trabajo de la Corporación, deberá redactarse una ley expropiatoria que establezca la expropiación de qué predios -conforme a las averiguaciones de la Corporación- será considerada de utilidad pública o interés nacional", Informe de la Comisión Verdad Histórica y Nuevo Trato con los Pueblos Indígenas, $1^{\mathrm{a}}$ ed., Santiago, 2008, p. 573

52 "La normativa nacional en esta materia tiene déficits que deben superarse. En este sentido el INDH ha sostenido que el Poder Ejecutivo y el Congreso deben avanzar en la generación de una legislación que establezca mecanismos que garanticen la restitución de las tierras tradicionales, según entiende por ellas el derecho internacional de los derechos humanos. En ese marco, y para el caso que dichas tierras estén inscritas a nombre de particulares, dicha legislación debe contemplar, entre otros mecanismos, las causales de expropiación que permitan la restitución eficaz de esas tierras indígenas con la correspondiente compensación a favor de terceros", Instituto Nacional de Derechos Humanos, Informe Anual 2012. Situación de los derechos bumanos en Chile, Santiago, 2012, p. 73.

53 Rodolfo Stavenhagen, Informe del Relator Especial sobre la situación de los derechos humanos y las libertades fundamentales de los indígenas sobre su visita a Chile, E/CN.4/2004/80/Add.3 (17 de noviembre de 2003), párr. 65; James Anaya, Informe del Relator Especial sobre la situación de los derechos humanos y las libertades fundamentales 
preferir la adquisición voluntaria reglada en la Ley $\mathrm{N}^{\circ} 19.253$, mecanismo que habría generado alteraciones en el mercado de la tierra y que ha sido objeto de críticas, tanto desde los propietarios no indígenas como desde las propias comunidades reclamantes. Aunque no es este el lugar para indagar las razones que explican esta opción, es probable que el análisis político de la envergadura de las demandas territoriales haya aconsejado mantener el cauce del conflicto dentro variables que convenientemente no dependen por completo de la agencia gubernamental encargada de conducirlo, a saber, (i) el que exista un tercer propietario con voluntad de vender, (ii) el que exista acuerdo sobre el precio y (iii) el que exista disponibilidad presupuestaria para atender el gasto. En efecto, como la demanda de restitución puede exceder la sola recuperación de las superficies amparadas por los títulos de merced otorgados al amparo de la legislación estatal del siglo XIX, es posible interpretar el silencio legislativo del último cuarto de siglo como una forma de evitar o al menos contener el escalamiento de una demanda que ha sido calificada, con una buena dosis de realismo, como "relativamente infinita" ${ }^{44}$. Después de todo, allí donde existen estos procedimientos expropiatorios se observa cierta presión por hacer uso de ellos y, consecuencialmente, efectos adversos sobre el valor del suelo y las inversiones. Probablemente por ello es que, como se ha observado en la experiencia comparada, los incentivos también apunten a la negociación o a la búsqueda de compensaciones alternativas 55 .

A continuación se mostrará la evolución de la legislación nacional, desde la primera mitad del siglo XX hasta el régimen jurídico vigente. Este último, como ya quedó dicho, no contiene disposiciones legales vigentes pero sí admite un análisis pertinente desde la perspectiva constitucional. Este último enfoque, como se demostrará, no impide una eventual iniciativa legislativa que califique el interés nacional para abrir paso a la expropiación con el fin de constituir propiedad indígena.

\section{Legislación preconstitucional}

Si se examina la legislación nacional anterior previa a 1973 es posible encontrar habilitaciones para expropiar tierras indígenas ${ }^{56}$ y autorizaciones para expropiar predios

de los indígenas, A/HRC/12/34/Add.6 (14 de septiembre 2009), párrs. 57-61; y Ben Emmerson, Informe del Relator Especial sobre la promoción y protección de los derechos humanos y las libertades fundamentales en la lucha contra el terrorismo, A/HRC/25/59/Add.2, 14 de abril de 2014, párr. 92.

${ }^{54}$ Donoso, Sebastián, “Tierras. Un escrutinio al núcleo inviolable de la identidad indígena”, en Derecho público iberoamericano 4 (2014), pp. 15-63, p. 61.

${ }^{55}$ En este sentido es ilustrativa la experiencia sudafricana, Atuahene, Bernadette, We Want What's Ours. Learning from South Africa's Land Restitution Program, Oxford University Press, Oxford, 2014, pp. 99-101. Atuahene explica que, si bien las agencias estatales tienen el poder de expropiar cuando no hay acuerdo respecto del precio, existen al menos tres cuantiosos incentivos para optar por soluciones alternativas: el efecto disuasivo que la expropiación puede tener sobre las inversiones, los gastos adicionales del procedimiento y las limitadas capacidades institucionales de gestión.

56 Es interesante el ejemplo de la Ley $\mathrm{N}^{\circ}$ 6.693, D. Of. de 11 de octubre de 1940, que declaró de utilidad pública los terrenos derivados del título de merced de J. Loncopán para fundar la ciudad de Calafquén. 
no indígenas con el objeto de constituir propiedades indígenas. En lo que aquí importa, es interesante destacar aquellas leyes que autorizaron la expropiación de predios para constituir dominio a favor de individuos o comunidades indígenas y que se mantuvieron formalmente vigentes hasta fines de la década del 70. En efecto, hasta 1979 la legislación chilena se encontraba dentro de aquel grupo de países con legislación indígena especializada y habilitante de las expropiaciones destinadas a constituir propiedad indígena.

En 1979 fue derogado por el D.L. 2.750 (D. Of. de 10 de julio de 1979) el Título I de la Ley $\mathrm{N}^{\circ} 17.729$ (D. Of. 26 de septiembre de 1972), cuyo art. 29 había declarado de utilidad pública e interés social los predios rústicos que la Corporación de la Reforma Agraria (CORA) estimara necesario transferir a campesinos indígenas, comunidades indígenas o cooperativas campesinas integradas por indígenas. Esta ley fue patrocinada por el gobierno del presidente Allende con el fin de producir un "aumento sustancial de la relación hombre-tierra", y advirtiendo que "la problemática de los grupos indígenas es distinta a la del resto del campesinado, por lo que debe ser observada y tratada con procedimientos y sistemas también distintos" ${ }^{57}$. Esta ley se unió a la normativa precedente sobre reforma agraria (Leyes $\mathrm{N}^{\text {os }} 14.511$ de 19621, 15.020 de 1962, y 16.640 de 1967) y, con las limitaciones pertinentes de su "corte campesinista" 58 , permitió un incremento relativamente significativo de las tierras indígenas hasta que se diera inicio a su proceso de reversión tras el golpe de Estado de $1973^{59}$. Así por ejemplo, solo entre 1970 y 1973 se expropió en las provincias de Malleco y Cautín una superficie aproximada de 636.288 hectáreas, de estas, los predios expropiados a favor de mapuches fue de 132.115 hectáreas ${ }^{60}$. Esta última cifra es muy parecida al total transferido a todos los pueblos indígenas bajo los veinte primeros años de vigencia de la Ley $\mathrm{N}^{\circ} 19.253^{61}$.

También puede citarse el caso de la Ley N 4.802, D. Of. de 24 de enero de 1930. Esta ley declaró de utilidad pública "los terrenos restituidos o que deban restituirse a los indígenas, en conformidad a las leyes sobre división de las comunidades, por los ocupantes y respecto de los cuales el Presidente de la República estime que existe utilidad general en que continúen en posesión de estos últimos” (art. 46).

${ }^{57}$ Mensaje, Cámara de Diputados, Diario de Sesiones, Legislatura 1970-1971, sesión 39ª 19 de mayo de 1971, III, pp. 2783-2784.

58 Muñoz, Bernardo, "Derechos de propiedad y pueblos indígenas en Chile”, en Cepal Serie Desarrollo Productivo 60 (1999), p. 16.

59 Sobre la reforma agraria el texto de referencia pertenece a Correa, Martín, Molina, Raúl y Yáñez, Nancy, La reforma agraria y las tierras mapuches. Chile 1962-1975, Lom, Santiago, 2005, pp. 71 y ss. pp. Véase también Berdichewsky, Bernardo, “The Araucanian Indian in Chile”, en IWGIA Document 20, 1975, pp. 17-30.

${ }^{60}$ Comisión Verdad Histórica y Nuevo Trato con los Pueblos Indígenas, Informe de la Comisión de Trabajo Autónomo Mapuche, Vol. III, Tomo II, p. 903. La cifra no desagrega las expropiaciones ejecutadas al amparo de la Ley $\mathrm{N}^{\circ} 17.729$ respecto de la legislación agraria general.

${ }^{61}$ De acuerdo con cifras de la CONADI (Ord. 926, 17 de octubre de 2014) entre 1994 y el 2013 se transfirieron 144.078 hectáreas merced del art. 20 de la Ley $\mathrm{N}^{\circ} 19.253$ (la cifra no incluye por tanto las hectáreas de transferencia fiscal). 


\section{Principios rectores bajo la Constitución política vigente}

\section{a) Viabilidad constitucional}

Tras las modificaciones legales de 1979 desaparecen las habilitaciones legales especiales para expropiar y constituir propiedad en favor de indígenas y solo restan las habilitaciones legales generales que permiten, como se recordará más adelante, al Estado o a instituciones descentralizadas la expropiación con fines habitacionales o de regularización general. La pregunta que surge por tanto, tras la constatación de la inexistencia de una habilitación legal expresa, es si ella resulta procedente bajo el imperio de la Constitución vigente. La tesis que aquí se sostiene es positiva.

En efecto, a diferencia de otras cuestiones, en lo que aquí importa el tenor de las causales de expropiación no varió entre las constituciones de 1925 y 1980 . Aunque la primera se refería expresamente al deber de propender a la "conveniente distribución de la propiedad y a la constitución de la propiedad familiar”, no parece haber razón para considerar que esa distribución de la propiedad no pudiese ser considerado como un asunto de "interés social” (Const. 1925) o "nacional” (Const. 1980) según el lenguaje de las propias constituciones. Si bien habría existido alguna variación respecto de estas últimas fórmulas, posiblemente explicadas por algún temor hacia lo "social" que hizo a los redactores preferir lo "nacional" 62 , pareciera que esa discusión fue superada tras la vigencia de la Convención Americana de Derechos Humanos, cuyo art. 21 hace simplemente referencia a la idea de "interés social". Lo nacional, como recuerda la doctrina nacional, rebasa lo estatal ${ }^{63} \mathrm{y}$, al igual que el concepto de "intereses generales de la nación”, puede concretarse en zonas geográficas determinadas del país ${ }^{64}$. Lo anterior, configurará en la práctica una expropiación a favor de un tercero, figura que cuenta con varios ejemplos en la legislación nacional, antes y después de la Constitución de $1980^{65}$.

No escapa a esta investigación el que la "distribución de la propiedad" fuese una fórmula incorporada al texto de la Constitución de 1925 en pleno debate ideológico sobre

${ }^{62}$ El proyecto de la Junta de Gobierno, al igual que el Acta Constitucional N 3 (DL. N N $^{\circ} 1.552$, D. Of. 13 de septiembre de 1976), se refería a la "causa de utilidad pública o interés social o nacional”. Fue en el Consejo de Estado donde se optó por eliminar la voz "social”. Véanse las aprensiones del consejero Ibáñez, en Arancibia, Jaime, Brahm, Enrique e Irarrázaval, Andrés (Eds.), Actas del Consejo de Estado en Chile (19761990), Centro de Estudios Bicentenario, 2008, tomo I, pp. 299-300. Sobre el particular, véase Peñailillo, Daniel, La expropiación ante en el Derecho civil, Ed. Jurídica, Santiago, $2^{\mathrm{a}}$ ed., 2004, p. 23.

${ }^{63}$ Vivanco, Ángela, Curso de Derecho constitucional. Aspectos dogmáticos de la Carta Fundamental de 1980, Ed. PUC, Santiago, 2006, Tomo II, p. 461.

${ }^{64}$ En este sentido, véanse Cea, José Luis, Derecho constitucional chileno, Ed. PUC, Santiago, 2012, $2^{\mathrm{a}}$ ed., Tomo II, p. 578 y Nogueira, Humberto, Derechos y garantías constitucionales, Librotecnia, Santiago, 2010, Tomo IV, p. 183. Cea sin embargo se muestra cauteloso de expropiaciones "diseñadas en beneficio solo privado, sea individual o de grupos identificados o en situación de serlo” (ibíd., p. 583).

${ }^{65}$ Véanse, a título ejemplar, las leyes $\mathrm{N}^{\circ} 16.391$ (D. Of. 16 de diciembre de 1965, art. 51, modificado por DL 1.523 de 31 de julio de 1976 y Ley No 19.021 de 3 de enero de 1991), 16.392 (D. Of. 15 de agosto de 1972 , arts. 30,32 y 38), 18.138 (D. Of. 25 de junio de 1982 , art. $7^{\circ}$ ) y $\mathrm{N}^{\circ} 18.777$ (D. Of. de 8 de febrero de 1989, art. 12). 
la reforma agraria (Ley de reforma constitucional $\mathrm{N}^{\circ} 16.615$, D. Of. de 20 de enero de $1967)^{66}$ y que, como prolongación de esa misma discusión, ella fuera suprimida por los redactores de la Constitución de 1980. Sin embargo, una interpretación evolutiva de la norma constitucional aconseja desembarazarse de los lastres de una intrincada interpretación originalista de un texto suprimido de la Carta de 1925 y sintonizar la cláusula del interés nacional con las obligaciones de reparación que asisten al Estado por la desapropiación de tierras indígenas. Esto significa comprender como un contenido posible del interés nacional un concepto que usualmente había competido él: el respeto por los derechos humanos en general y la obligación de reparación por desposesión de la tierra.

Por todo lo anteriormente señalado, no se comparte el modo en que el Tribunal Constitucional resolvió la disputa de constitucionalidad que, durante la tramitación de la aprobación parlamentaria, se planteó al art. 14.3 del Convenio No 169. El requerimiento concretamente reprochó a la norma atribuir al Estado "una obligación de expropiar a solicitud de un ente colectivo y en beneficio de este, lo que transgrede el marco conceptual de la expropiación en Chile y genera un elemento que profundizará la inestabilidad de los bienes raíces rurales" ${ }^{27}$. Resolviendo esta disputa el Tribunal la rechaza por dos argumentos que, como se ha sostenido en otro lugar ${ }^{68}$, no parecen apropiados: el carácter supuestamente programático de la regla y la inexistencia de una autorización constitucional para ese tipo de expropiaciones ${ }^{69}$. Contra lo que sostiene el Tribunal Constitucional -y como se recordó más arriba- la figura de las expropiaciones a favor de un tercero no son extrañas a nuestra legislación y ella se justifican, precisamente, en razones de utilidad pública (como acontece, por ejemplo, con las obras de infraestructura sanitaria) o de interés nacional.

${ }^{66}$ Véase, con referencias bibliográficas, Carrasco, Sergio, Génesis y vigencia de los textos constitucionales chilenos, Ed. Jurídica de Chile, Santiago, 2002, tercera ed., pp. 184-185 y Gómez Leyton, Juan C., La frontera de la democracia. El derecho de propiedad en Chile 1925-1973, Lom, Santiago, 2004, pp. 275-282.

${ }^{67}$ Requerimiento de 7 de julio de 2000, causa rol 309-00, disponible en www.tribunalconstitucional.cl.

68 Núñez, Manuel, "El derecho a la consulta previa en el Convenio 169 de la OIT. Notas para su implementación en Chile. Comentario”, en Contesse, Jorge (Ed.), El Convenio 169 de la OIT y el Derecho chileno. Mecanismos y obstáculos para su implementación, Ed. UDP, Santiago, 2012, pp. 232-234 y "Las representaciones internas del Derecho internacional. Control preventivo e inaplicabilidad de los tratados internacionales en la jurisprudencia del Tribunal Constitucional”, en Marshall, Pablo (Ed.), Jurisprudencia constitucional destacada. Análisis crítico, AbeledoPerrot/LegalPublishing, Santiago, pp. 21-23

69 "Que en cuanto a la inconstitucionalidad que se le imputa al Convenio, en relación a la necesidad de expropiar tierras para ser entregadas a los pueblos indígenas, además de la razón antes mencionada, esto es, que el Convenio no ejecuta por sí mismo las medidas sino que invita al Estado a ponerlas en ejecución, debe precisarse que los procedimientos necesarios para implementarlas, deben ajustarse al marco del sistema jurídico nacional en el que, ni la Constitución Política ni la ley, dan cabida a expropiaciones para tal efecto.

Por el hecho de ser programática la norma y atendido que lo que ella propone no queda comprendido en el marco del sistema jurídico nacional de expropiaciones, el tratado en esta parte tampoco vulnera el artículo $19, \mathrm{~N}^{\circ} 24^{\circ}$, de la Carta Fundamental”, Tribunal Constitucional, sentencia de 4 de agosto de 2000, rol 309 , cons. $66^{\circ}$. 
b) Derechos del expropiado: control de la habilitación legal y de la toma de posesión material del inmueble

Los derechos del sujeto expropiado quedan sujetos al régimen constitucional general. Con relación a estas exigencias es posible hacer dos precisiones relacionadas con el posible control de la habilitación legal y con parte del régimen específico de los derechos asociados a la toma de posesión material del inmueble. Estas dos cuestiones pueden ser relevantes y adquirir una connotación específica tratándose del manejo de conflictos que, de ordinario, no tienen una sola parte ni un solo interés público comprometido.

Con relación al control de la habilitación legal, este será siempre posible en la fase de tramitación legislativa o, en su dimensión aplicativa, durante una eventual gestión judicial mediante un recurso de inaplicabilidad. En estos casos es posible que las leyes habilitantes particulares estén sujetas a un mayor escrutinio que las generales. En efecto, respecto de la legislación particular -que califica el interés nacional o la utilidad pública de un bien determinado- cabrá analizar si, además de los requisitos formales, se cumple con el estándar sustantivo de la proporcionalidad. Este último análisis, que excede el objeto de la presente investigación, debe ser analizado a la luz del caso concreto (doblemente concreto, en sede preventiva y represiva) y teniendo en cuenta la deferencia que, respecto de decisiones políticas o de mérito, debe la judicatura constitucional al legislador. La desproporción debería ser -parafraseando el estándar comparado de Wednesbury-visible para cualquier buen (y por tanto razonable) padre o madre de familia ${ }^{70}$. Para valorar este último criterio deberán ponderarse diversos elementos, entre ellos cabría destacar la eventual condena de un tribunal internacional, el número de personas beneficiadas versus las afectadas y la significación que la tierra tiene para los sujetos en conflicto (incluida aquí la posibilidad o imposibilidad de sobrevivencia de los grupos separados de las tierras reclamadas).

Por último, con relación al ejercicio de los derechos del expropiado es factible recordar que a este le asiste el derecho a la indemnización, el derecho a la objeción de la legalidad del acto expropiatorio y el derecho a condicionar la toma de posesión material al pago de la indemnización provisoria. Este último derecho -que persigue evitar la aprehensión anticipada de la cosa y también la autotutela- debería eventualmente desincentivar las ocupaciones materiales (o "recuperaciones") mientras se encuentra pendiente el proceso de expropiación. En efecto, antes de constituirse en un procedimiento de regularización de ocupaciones materiales, la garantía de la expropiación persigue que la posesión material suceda -y no preceda- a ciertas actuaciones legislativas y administrativas que, a la vez de promover el interés nacional o la utilidad pública, respeten los derechos del expropiado $^{71}$. Hasta que la desposesión material no se produzca de forma conforme a derecho, asisten al expropiado todos su derechos de ocupación, incluyendo ciertamente

${ }^{70}$ Acerca de proporcionalidad, sigue siendo útil el estándar de la sentencia rol $\mathrm{N}^{\circ} 790$ del Tribunal Constitucional, 11 de diciembre de 2007 , cons. $22^{\circ}$ y ss.

${ }^{71}$ Entre la incipiente doctrina que existe respecto de esta materia en el Tribunal Constitucional, debe destacarse la disidencia del Ministro Romero en los fallos roles $\mathrm{N}^{\text {os }} 2.751$ (7 de julio de 2015 ) y 2.769 (28 de 
el de acceso a la justicia para recuperarla o hacer efectiva la responsabilidad que pudieren tener quienes lo impiden ${ }^{72}$. Por otra parte, de existir desposesión material previa y al margen de lo exigido por normativa expropiatoria, la compensación pecuniaria del perjuicio patrimonial efectivamente causado debería cubrir también ese ítem. Si bien hay alguna dificultad normativa para incorporar esta última indemnización en el procedimiento expropiatorio y sus respectivos reclamos (dificultad en todo caso superable por medio de un ejercicio de interpretación que no puede ser desarrollado en este trabajo), al menos ella encuentra sustento en la idea de responsabilidad civil.

\section{CONCLUSIONES}

a) La desposesión de tierras indígenas ocasiona para el Estado el deber de generar procedimientos de derecho interno para encauzar las demandas de restitución. Este deber no está sujeto a plazo, sin perjuicio que el tiempo pueda incidir afirmativamente en la opción por formas de reparación diferentes a la restitución.

b) En el acervo doctrinario de los órganos de supervisión de tratados de derechos humanos se ha configurado un derecho a la restitución como parte de los derechos sobre la tierra indígena. Este derecho, también llamado de recuperación, está sujeto a la ponderación con otros derechos respecto de los cuales no goza de primacía o preferencia predeterminada. Este proceso de ponderación corresponde, de buena fe, a los Estados que deben valorar públicamente las razones objetivas que pudieren preferir otras formas de compensación, diversas a la restitución. Lo anterior, puede condicionar en ciertos casos la configuración de un verdadero derecho a la restitución a una decisión política $-y$, por tanto, jurídicamente no obligatoriadel Estado.

c) En caso que la propiedad originariamente indígena hubiese sido radicada en un patrimonio distinto del estatal, se admite en el derecho internacional la posibilidad de recurrir a la expropiación como instrumento que permita a los gobiernos canalizar la restitución con sujeción a las garantías del derecho de propiedad privada reconocido en las constituciones y en el Pacto de San José de Costa Rica. Se aplican en este caso los estándares de protección de la propiedad y las garantías de la inviolabilidad de la propiedad.

julio de 2015), que precisamente ha apuntado a la improcedencia constitucional de los hechos consumados frente a la tutela de la propiedad privada.

72 Es llamativa, a este respecto, la doctrina de la Corte IDH. Este Tribunal ha expresado preocupación frente al ejercicio de la acciones penales y civiles que le asisten a los propietarios hasta que no sean regularmente expropiados: "Resulta preocupante que quienes detentaban títulos de propiedad en ese entonces iniciaron procesos civiles y penales contra los miembros de la Comunidad, a pesar de lo dispuesto en la Sentencia de fondo correspondiente al caso Sawhoyamaxa", Corte IDH, Caso de las comunidades indígenas Yakye Axa, Sawhoyamaxa y Xákmok Kásek v. Paraguay, Supervisión de cumplimiento de sentencia, resolución de 24 de junio de 2015, párr. 23. 
d) Entre los países del continente americano que han ratificado el Convenio $\mathrm{N}^{\circ} 169$ de la OIT se advierte, sin calificar la legislación en términos cuantitativos y cualitativos, una tendencia hacia admitir la expropiación a favor de comunidades indígenas. Esta legislación bien puede asumir la forma de normas agrarias, de normativa indígena general o de normativa indígena especial. Estas normas se inscriben, ciertamente, dentro de las normas y tradiciones constitucionales que cada país tiene respecto del instituto expropiatorio.

e) En Chile, tras las reformas legislativas de fines de la década de los setenta, no existe norma habilitante especial que faculte al Estado o a alguna agencia descentralizada para expropiar con el objeto de permitir la restitución de tierras. Lo anterior hace necesario juzgar la viabilidad constitucional de esta potestad exorbitante de la Administración. La tesis que se ha defendido en este trabajo es la constitucionalidad de esta medida.

f) En caso de aprobarse una ley general o especial que autorice la expropiación, se estiman aplicables todos los derechos que la Constitución y que la normativa legal reconoce al expropiado. Este último, además de impugnar la constitucionalidad de la ley habilitante (especialmente si ella fuere especial), se encuentra protegido por los derechos que le asisten respecto de la toma de posesión material del inmueble.

\section{BIBLIOGRAFÍA}

\section{a) Textos}

Alexander, Gregory, “The Limits of Property Reparations”, en Cornell Law School Legal Studies Research Papers 5 (2004), pp. 1-18, Disponible en: http://scholarship.law.cornell.edu/cgi/ viewcontent.cgi ?article $=1023 \&$ context $=$ lsrp_paper.

Anaya, James, Indigenous Peoples and International Law, Oxford University Press, New York, 2004.

ANAYA, James, Informe del Relator Especial sobre la situación de los derechos humanos y las libertades fundamentales de los indígenas, A/HRC/12/34/Add.6 (14 de septiembre 2009).

Arancibia, Jaime, Brahm, Enrique e Irarrázaval, Andrés (Eds.), Actas del Consejo de Estado en Chile (1976-1990), Centro de Estudios Bicentenario, 2008.

Asamblea General de Naciones Unidas, Resolución 60/147, 16 de diciembre de 2005 "Principios y directrices básicos sobre el derecho de las víctimas de violaciones manifiestas de las normas internacionales de derechos humanos y violaciones graves del derecho internacional humanitario a interponer recursos y obtener reparaciones".

Atuahene, Bernadette, We Want What's Ours. Learning from South Africa's Land Restitution Program, Oxford University Press, Oxford, 2014,

Aylwin, José, El derecho de los pueblos indígenas a la tierra y al territorio en América Latina: Antecedentes bistóricos y tendencias actuales, OEA, 2003. Disponible en: http://www.archivochile.com/ Ideas_Autores/aylwino_j/aylwinoj0002.pdf.

Aylwin, José, Meza-Lopehandía, Matías y Yáñez, Los pueblos indígenas y el derecho, Lom, Santiago, 2013.

Berdichewsky, Bernardo, "The Araucanian Indian in Chile", en IWGIA Document 20, 1975, pp 2-40, disponible en: http://www.iwgia.org/iwgia_files_publications_files/0195_20Chile.pdf. 
Buyse Antoine, "Lost and Regained? Restitution as a Remedy for Human Rights Violations in the Context of International Law", en Zeitschrift für Auslandisches Öffentliches Recht und Völkerrecht 68 (2008), pp. 129-153.

Carrasco, Sergio, Génesis y vigencia de los textos constitucionales chilenos, Ed. Jurídica de Chile, Santiago, 2002, tercera ed.

Cea, José Luis, Derecho constitucional chileno, Ed. PUC, Santiago, 2012, 2a ed., Tomo II.

CEACR Observación, 2009, Publicación 99ª Reunión CIT (2010), México.

CEACR, Solicitud directa, adopción: 2008, publ.: 98 ${ }^{\mathrm{a}}$ Reunión CIT (2009), Paraguay.

CEACR, Solicitud directa, adopción: 2013, publ.: 103ª Reunión CIT (2014), México.

CEACR, Solicitud directa, adopción: 2014, publ.: 104ª Reunión CIT (2015), Paraguay.

Charters, Claire, "Reparations for Indigenous Peoples: Global International Instruments and Institutions", en Lenzerini, Federico (Ed.), Reparations for Indigenous Peoples. International E Comparative Perspectives, cit. nt. XXX, pp. 163-195.

$\mathrm{CIDH}$, Derechos de los pueblos indígenas y tribales sobre sus tierras ancestrales y recursos naturales. Normas y jurisprudencia del sistema interamericano, OEA/Ser. L./V/II, Doc. 56/09, 30 de diciembre de 2009.

CIDH, Pueblos indígenas. Comunidades afrodescendientes. Industria extractiva. OEA/Ser. L./V/II, Doc. 47/15, 31 de diciembre de 2015.

Comisión Verdad Histórica y Nuevo Trato con los Pueblos Indígenas, Informe, $1^{\text {a }}$ ed., Santiago, 2008.

Comisión Verdad Histórica y Nuevo Trato con los Pueblos Indígenas, Informe de la Comisión de Trabajo Autónomo Mapuche, Vol. III, Tomo II.

Conferencia Internacional del Trabajo, Informe de la Comisión del Convenio núm. 107, Actas Provisionales, 75ª Reunión, Ginebra, 1988.

Conferencia Internacional del Trabajo, $76^{\mathrm{a}}$ Reunión, Ginebra, 1989, Informe IV (2a), Revisión parcial del Convenio sobre poblaciones indígenas y tribuales, 1957 (núm. 107).

Correa, Martín, Molina, Raúl y Yáñez, Nancy, La reforma agraria y las tierras mapuches. Chile 1962-1975, Lom, Santiago, 2005.

Donoso, Sebastián, "Tierras. Un escrutinio al núcleo inviolable de la identidad indígena”, en Derecho público iberoamericano 4 (2014), pp. 15-63.

Duffy, Aoife, “Indigenous Peoples' Land Rights: Developing a Sui Generis Approach to Ownership and Restitution”, International Journal on Minority and Group Rights 15 (2008), pp. 505-538.

EMmerson, Ben, Informe del Relator Especial sobre la promoción y protección de los derechos humanos y las libertades fundamentales en la lucha contra el terrorismo, A/HRC/25/59/ Add.2, 14 de abril de 2014.

Francioni, Francesco, "Reparation for Indigenous Peoples: Is International Law Ready to Ensure Reddress for Historical Injustices", en Lenzerini, Federico (Ed.), Reparations for Indigenous Peoples. International \& Comparative Perspectives, Oxford University Press, Oxford, 2009, pp. 27-45.

Gilbert, Jérémie, Indigenous People's Land Rights under International Law. From Victims to Actors, Transnational Publ., Ardsley, 2006.

Gómez Isa, Felipe, "El derecho de los pueblos indígenas a la reparación por injusticias históricas”, en Álvarez, Natalia, Oliva, Daniel y Zúñiga, Nieves (Eds.), Declaración sobre los derechos de los pueblos indígenas. Hacia un mundo intercultural y sostenible, Catarata, Madrid, 2009, pp. 157-191.

Gómez Leyton, Juan C., La frontera de la democracia. El derecho de propiedad en Chile 1925-1973, Lom, Santiago, 2004. 
Instituto Nacional de Derechos Humanos, Informe Anual 2012. Situación de los derechos humanos en Chile, Santiago, 2012.

Jung, Courtney, "Canada and the Legacy of the Indian Residential Schools: Transitional Justice for Indigenous Peoples in a Nontransitional Society”, en Paige, Arthur (Ed.), Identities in Transition. Challenges for Transitional Justice in Divided Societies, Cambridge University Press, Cambridge, pp. 217-250.

Kuti, Csongor, Post-Communist Restitution and the Rule of Law, Central Europe University Press, Budapest-New York, 2009.

Lenzerini, Federico, "Reparations for Indigenous Peoples in International and Comparative Law", en Lenzerini, Federico (Ed.), Reparations for Indigenous Peoples. International E Comparative Perspectives, Oxford University Press, Oxford, 2009, pp. 3-26.

Lira, Elizabeth y Loveman, Brian, Políticas de reparación. Chile 1990-2004, Lom, Santiago de Chile, 2005.

MACKAY, Fergus, Los derechos de los pueblos indígenas en el sistema internacional, APRODEH, Lima, 1999.

Martín Beristain, Carlos, "Derecho a la reparación en los casos indígenas", en Gómez, Felipe y Berraondo, Mikel (Eds.), Los derechos indígenas tras la Declaración. El desafío de la implementación, Publicaciones de la Universidad de Deusto, Bilbao, 2013, pp. 323-344.

MarTínez, Paula, The Victims and Land Restitution Law in Colombia. An analysis of the contradictions between the agrarian model and compensation for the victims, FDCL, Berlín, 2013.

MuÑoz, Bernardo, "Derechos de propiedad y pueblos indígenas en Chile”, en Cepal Serie Desarrollo Productivo 60 (1999), pp. 1-49.

Nogueira, Humberto, Derechos y garantías constitucionales, Librotecnia, Santiago, 2010, Tomo IV.

NúÑEZ, Manuel, "El derecho a la consulta previa en el Convenio 169 de la OIT. Notas para su implementación en Chile. Comentario", en Contesse, Jorge (Ed.), El Convenio 169 de la OIT y el Derecho chileno. Mecanismos y obstáculos para su implementación, Ed. UDP, Santiago, 2012 , pp. 232-240.

NúÑEZ, Manuel, "Las representaciones internas del Derecho internacional. Control preventivo e inaplicabilidad de los tratados internacionales en la jurisprudencia del Tribunal Constitucional”, en Marshall, Pablo (Ed.), Jurisprudencia constitucional destacada. Análisis crítico, AbeledoPerrot/LegalPublishing, Santiago, pp. 19-36.

OIT, Departamento de Normas internacionales del Trabajo, Los derechos de los pueblos indígenas y tribales en la práctica. Una guía sobre el Convenio núm. 169 de la OIT, Ginebra, 2009.

Pentassuglia, Gaetano, “Towards a Jurisprudential Articulation of Indigenous Land Rights”, en The European Journal of International Law 22/1 (2011), pp. 165-202.

PeÑallillo, Daniel, La expropiación ante en el Derecho civil, Ed. Jurídica, Santiago, $2^{a}$ ed., 2004.

Shelton, Dinah, Remedies in International Human Rights Law, Oxford University Press, Oxford, 2015, tercera edición.

Stavenhagen, Rodolfo, Informe del Relator Especial sobre la situación de los derechos humanos y las libertades fundamentales de los indígenas sobre su visita a Chile, E/CN.4/2004/80/Add.3 (17 de noviembre de 2003).

Swepston, Lee, "A New Step in the International Law on Indigenous and Tribal Peoples: ILO Convention No. 169 of 1989", en Anaya, James (Ed.), International Law and Indigenous Peoples, Ashgate/Darmouth, Aldershot, 2003, pp. 329-366.

Vivanco, Ángela, Curso de Derecho constitucional. Aspectos dogmáticos de la Carta Fundamental de 1980, Ed. PUC, Santiago, 2006, Tomo II.

WALDRON, Jeremy, “Superseding Historic Injustice”, en Ethics 103/1 (1992), pp. 4-28. 


\section{b) Jurisprudencia citada}

Corte IDH, caso Caso Comunidad indígena Yakye Axa v. Paraguay. Fondo, reparaciones y costas, sentencia de 17 de junio de 2005.

Corte IDH, caso Comunidad Garífuna de Punta Piedra y sus miembros vs. Honduras. Excepciones preliminares, fondo, reparaciones y costas, sentencia de 8 de octubre de 2015.

Corte IDH, caso Comunidad Indígena Sawhoyamaxa v. Paraguay. Fondo, Reparaciones y Costas, sentencia de 29 de marzo de 2006.

Corte IDH, caso Comunidad Indígena Xákmok Kásek v. Paraguay. Fondo, reparaciones y costas, sentencia de 24 de agosto de 2010.

Corte IDH, caso de la Comunidad Moiwana, Fondo, reparaciones y costas, sentencia 15 de junio de 2005.

Corte IDH, Caso de las comunidades indígenas Yakye Axa, Sawhoyamaxa y Xákmok Kásek v. Paraguay, Supervisión de cumplimiento de sentencia, resolución de 24 de junio de 2015.

Corte IDH, Caso de los pueblos Kuna de Madungandí y emberá de Bayano y sus miembros v. Panamá. Excepciones preliminares, fondo, reparaciones y costas, sentencia de 14 de octubre de 2014.

Corte IDH, caso Pueblos Kaliña y Lokono v. Surinam. Fondo, reparaciones y costas, sentencia de 29 de noviembre de 2015

Corte IDH, caso Velásquez Rodríguez v. Honduras. Reparaciones y Costas, sentencia de 21 de julio de 1989, párr. 25.

CORTE Internacional de Justicia, Opinión consultiva sobre las consecuencias jurídicas de la construcción de un muro en el territorio palestino ocupado, 9 de julio de 2004, A/ES-10/273.

Corte Suprema de Justicia de Mendoza, sentencia núm. 72.575, de 18 de diciembre de 2008, Sala segunda, segunda circunscripción.

Corte Suprema de Paraguay, acuerdo y sentencia núm. 981, 30 de septiembre de 2014, acción de inconstitucionalidad "Kansol S.A. y Roswell Co. S.A. c. Ley núm. 5.194 que declara de interés social y expropia a favor del Instituto Paraguayo del Indígena".

Tribunal Constitucional, rol núm. 2.751, sentencia de 7 de julio de 2015.

Tribunal Constitucional, rol núm. 2.769, sentencia de 28 de julio de 2015.

Tribunal Constitucional, rol núm. 309, sentencia de 4 de agosto de 2000.

Tribunal Constitucional, rol núm. 790, sentencia de 11 de diciembre de 2007. 
